\title{
Use and abuse of cotton buds
}

\author{
Jonathan C Hobson MA MRCS Jeremy A Lavy FRCS
}

J R Soc Med 2005;98:360-361

\section{SUMMARY}

Ear injuries caused by cotton buds are commonly seen in ear, nose and throat (ENT) practice. We asked 1000 patients attending an ENT referral clinic whether they used cotton buds to clean the ear canal. Of the 325 who responded, 171 said they did. The frequency of use was no higher in those with ear complaints than in those with nose and other complaints. $15-20 \%$ of respondents disagreed with the statements that cotton buds can cause infections, wax impaction or perforations. On the evidence of this survey, manufacturers' warnings need to be fortified.

\section{INTRODUCTION}

Cotton buds were developed in 1923 by Leo Gerstenzang. ${ }^{1}$ After observing his wife using wads of cotton on toothpicks to clean his baby's ears, he developed a cotton-tipped swab that he considered safer. The product was initially called Qtips Baby Gays (Q for quality) and Q-tips survive to this day. The first instances of medical concern over the use of cotton buds were in 1972 with reports of tympanic membrane perforation, otitis externa ${ }^{2}$ and cerumen impaction. ${ }^{3}$ Manufacturers then advised against use of cotton buds in the external auditory canal. Nonetheless, cotton-bud-related injuries are a common reason for attendances at ear, nose and throat (ENT) referral clinics. ${ }^{4}$ We asked patients attending an ENT clinic about the practice.

\section{METHODS}

All patients attending an ENT urgent referral clinic in two months were invited to complete an anonymous questionnaire (available from authors). About 500 patients attended per month and 325 responded, with some questions answered according to a 5-point Likert scalestrongly disagree, disagree, not sure/neutral, agree, strongly agree. We also wrote to nine manufacturers and retailers of cotton buds inquiring about the wording of any warnings on packaging and how long such a warning had been present. For the two who did not reply, we made our own purchases.

Royal National Throat Nose \& Ear Hospital, 330 Gray's Inn Road, London WC1X 8DA, UK

Correspondence to: Jonathan Hobson, 20 Claremont Grove, Manchester M20 2GL, UK

E-mail: jchobson@doctors.org.uk

\section{RESULTS}

325 patients, 173 male, answered the questionnaire, average age 41 years (range 9-92). In 232 patients the symptoms were ear-related, in 40 nasal, in 31 throat and in

\begin{tabular}{lr}
$\begin{array}{l}\text { Table } 1 \text { Patients' reasons for using cotton buds } \\
\text { in the ear canal }\end{array}$ & No. (\%) \\
\hline Reason & $3(2)$ \\
\hline Advertising & $5(3)$ \\
Advised by a doctor & $3(2)$ \\
Advised by a nurse & $42(25)$ \\
Family and friends use them & $89(52)$ \\
Because it seems like a good idea & $20(12)$ \\
Not sure & $9(5)$ \\
No reply &
\end{tabular}

Table 2 Responses of users and non-users to statements about ear cleaning (Likert scale grading)

\begin{tabular}{|c|c|c|}
\hline Question & Users & $\begin{array}{l}\text { Non- } \\
\text { users }\end{array}$ \\
\hline Cotton buds should be used to clean the ears & 3.47 & 2.18 \\
\hline $\begin{array}{l}\text { A damp towel or flannel should be used } \\
\text { to clean the ears }\end{array}$ & 2.98 & 2.99 \\
\hline Just water should be used to clean the ears & 2.70 & 2.81 \\
\hline It is best not to clean the ears & 2.20 & 3.09 \\
\hline Cotton buds are effective at removing ear wax & 3.81 & 2.46 \\
\hline Cotton buds can cause infections of the ear & 3.09 & 3.75 \\
\hline $\begin{array}{l}\text { Cotton buds can cause a perforation (hole) } \\
\text { of the eardrum }\end{array}$ & 3.34 & 3.92 \\
\hline $\begin{array}{l}\text { Cotton buds can push ear wax deeper into } \\
\text { the ear }\end{array}$ & 3.54 & 4.01 \\
\hline
\end{tabular}




\begin{tabular}{|c|c|c|}
\hline Company & Warning & $\begin{array}{l}\text { Time warning } \\
\text { present }\end{array}$ \\
\hline Asda & 'Always take care not to push cotton buds into the inner ear or nose canals' & Many years \\
\hline Boots & 'Cosmetic buds should not be inserted into the ear canal' & No reply \\
\hline Johnson \& Johnson & $\begin{array}{l}\text { 'Never insert a cotton bud into the inner ear or nose. Keep out of children's reach. } \\
\text { Improper use can cause injury' }\end{array}$ & Since 2001 \\
\hline Morrisons & 'Do not place in ear canal or nose' & $\begin{array}{l}\text { As long as product } \\
\text { has been available }\end{array}$ \\
\hline Safeway & [Taken over by Morrisons] & \\
\hline Sainsbury & 'Cotton buds should not be inserted into the ear canal' & 'For years' \\
\hline Superdrug & $\begin{array}{l}\text { 'Use to gently clean around the outer surface of the ear, do not probe into the ear } \\
\text { canal itself' }\end{array}$ & Not stated \\
\hline Tesco & 'Do not insert bud into the ear canal' & No reply \\
\hline Waitrose & 'Cotton buds should not be inserted into the ear canal' & Since 2000 \\
\hline
\end{tabular}

22 other. 171 (53\%) respondents said they used cotton buds to clean their ears, and the frequency in those with ear symptoms was about the same in those with other complaints. Table 1 lists reasons for cotton bud use. Likert scale responses to a series of statements are summarized in Table 2. Concerning the potential complications of cotton bud use, the numbers expressing ignorance ('strongly disagree' or 'disagree') were: 'can cause infections of the ear' 64, 'can cause a perforation of the eardrum' 51, 'can push ear wax deeper into the ear' 47 . The warnings of nine companies are shown in Table 3.

\section{DISCUSSION}

Ear wax is a mixture of ceruminous gland secretions, squames of epithelium, dust and other foreign debris. ${ }^{5}$ It is expelled by epithelial migration from the tympanic membrane, aided by movements of the temporomandibular joint. ${ }^{6}$ This process renders the ear 'self-cleaning'. Unwise efforts with a cotton bud can produce wax plug impaction, with resultant discomfort, deafness and vertigo, ${ }^{7}$ injury to the external auditory canal or perforation of the tympanic membrane. ${ }^{2,8}$ Otitis externa can likewise be caused by overzealous use of cotton buds. ${ }^{9}$

The survey reported here is best regarded as qualitative. The response rate was too low for quantitative validity, and we cannot tell whether the behaviour of the ENT patients typified that of the wider population - or whether, indeed, some of them had cotton-bud-induced disorders. What the survey does indicate is that warnings against use in the ear canal are quite widely discounted or ignored. Most cotton bud users, when asked why they did it, merely said 'it seems like a good idea' or family and friends use them. Fortunately, only a small number had been advised to do so by medical professionals. We have to admit that a large number of people use cotton buds without coming to harm and the actual risk remains to be elucidated. Cotton bud manufacturers are explicit in their warnings against use in the ear, but on the evidence of this survey these warnings need to be stronger.

Acknowledgments We thank Ellen Jones, Julio Rodriguez, Abdul Beebeejaun and Veenawyn Seeram for help in collating patient questionnaires and Mr Henry Grant for suggestions on the study design.

\section{REFERENCES}

1 Q-tips, 2004 [www.qtips.com]

2 Robertson MS. The misuse of cotton wool buds. N Z Med J 1972;75:37

3 Barton RT. Q-tip otalgia. JAMA 1972;220:1619

4 Steele BD, Brennan PO. A prospective survey of patients with presumed accidental ear injury presenting to a paediatric accident and emergency department. Emerg Med J 2002;19:226-8

5 Hanger HC, Mulley GP. Cerumen: its fascination and clinical importance: a review. J R Soc Med 1992;85:347-9

6 Anonymous. Wax in the ear. BMJ 1972;4:623-4

7 Sim DW. Wax plugs and cotton buds. J Laryngol Otol 1988;102:575-6

8 Kravitz H, Neyhus AI, Dale DO, Laker HI, Gomberg RM, Korach A. The cotton-tipped swab: a major cause of ear injury and hearing loss. Clinical Pediatr 1974;13:965-70

9 Nussinovitch M, Rimon A, Volovitz B, Raveh E, Prais D, Amir J. Cotton-tip applicators as a leading cause of otitis externa. Int J Pediatr Otorhinolaryngol 2004;68:433-5 